\title{
Foods, nutrients or whole diets: effects of targeting fish and LCn3PUFA consumption in a 12 mo weight loss trial
}

Linda C Tapsell, Marijka J Batterham, Karen E Charlton, Elizabeth P Neale, Yasmine C Probst, Jane E O'Shea, Rebecca L Thorne, Qingsheng Zhang and Jimmy Chun Yu Louie

\begin{abstract}
Background: There is some evidence in the literature that emphasising fish consumption may assist with weight loss. The aim was to assess the effects of advice to consume 2 fish meals per week in a weight loss diet.

Methods: A parallel randomised placebo-controlled trial was conducted in 118 obese Australian adults (mean BMl \pm SD $31.3 \pm 3.5 \mathrm{~kg} / \mathrm{m}^{2}$; mean age \pm SD $45 \pm 10$ y; 28\% male). Participants received low calorie dietary advice + placebo (1 g olive oil; Control), low calorie dietary advice emphasising fish + placebo (Fish), or low calorie dietary advice emphasising fish diet + LCn3PUFA supplements (Fish + S). Individualised advice targeted $2 \mathrm{MJ}$ energy deficit (30\%E fat, 45\%E carbohydrate and 25\%E protein) with or without two servings (180 g) fatty fish/wk.

Results: All groups lost weight at 12 months (Control $-4.5 \mathrm{~kg}$ vs. Fish $-4.3 \mathrm{~kg}$ vs. Fish $+\mathrm{S}-3.3 \mathrm{~kg} ; p<0.001$ ) and percentage body fat (Control: $-1.5 \%$ vs. Fish: $-1.4 \%$ vs. Fish + S: $-0.7 \% ; p<0.001$ ) but there were no significant differences between groups. Cardiovascular disease risk factors changed as expected from weight loss.
\end{abstract}

Conclusions: Advice to consume 2 fish meals per week did not enhance the effects on weight loss of a healthy low calorie diet.

Trial registration: ACTRN12608000425392.

Keywords: Randomised controlled trial, LCn-3PUFA, Fish, Weight loss

\section{Background}

Dietary guidance draws on evidence of health effects from foods, nutrients and whole diets [1,2], yet that these are all inter-related. There are calls for a greater emphasis on food in the construction of dietary guidelines [3] and this has implications for nutrition research, particularly with the concurrent need to address the obesity problem. Weight management reflects total energy intake which is delivered by the whole diet. Evidence for differential effects of single foods may be difficult to demonstrate when total dietary energy is kept below requirements. In addition, trial participants may choose foods and dietary patterns that are not fully compliant with the treatment, and in many cases the results reflect effects of dietary advice strategies, not of the foods, diets or nutrients

\footnotetext{
* Correspondence: Itapsell@uow.edu.au

Smart Foods Centre, University of Wollongong, Northfields Avenue, Wollongong NSW 2522, Australia
}

targeted, (for example see [4]). Nevertheless, evidence based statements can be found drawing on literature that shows effects and associations between food intakes and health outcomes including weight management [5].

LCn3PUFA is an example of a key nutrient that has been implicated in weight loss. Observational studies show a relationship between LCn3PUFA status and a healthier BMI [6], and body composition [7]. Small, short term experimental studies show that a dose of $1.8 \mathrm{~g}$ LCn3PUFA /day can preferentially decrease adiposity [8] and increase fat oxidation [9]. This research suggests plausible mechanisms of nutrient action, but this research has not translated to consistent clinical outcomes. One study has shown that doses of around 3 g LCn3PUFA /day can enhance weight loss [10] but others testing the same dose [11] or as $1.4 \%$ energy [12] have not found no effect. From a food perspective, LCn3 PUFA are primarily found in fish, so further research 
examining effects of fish consumption may be informative. One short term study found that eating oily fish or taking supplements may be equally beneficial in achieving a greater weight loss, at least in fish eating populations [13].

Mechanistic and short term studies provide evidence at a proof of concept level [14], but for dietary guidance, weight loss maintenance is the major health goal. Long term dietary trials are difficult to conduct and a loss to follow up can be expected [15] with publications showing a range of reporting [16]. In addition, translating the concept from mechanistic and short term studies also means testing an appropriate amount of food and/or supplements which might align with current recommendations. In terms of LCn3PUFA and fish, this is about $600 \mathrm{mg}$ LCn3PUFA or 2 fish meals/week [17]. The aim of the study reported here was to assess the effects on long term weight loss of advice to consume low calorie diets emphasising 2 fish meals per week with or without active supplements delivering equivalent amounts of LCn3PUFA.

\section{Methods}

\section{Study design}

A 12 month randomised controlled trial was conducted between 2009-2010 with overweight adults in three parallel diet advice arms: low calorie + placebo (control); low calorie + fish + placebo (Fish); and low calorie + fish + eicosapentaenoic acid (EPA)/docosahexanoic acid (DHA) supplements $($ Fish $+\mathrm{S})$. The second intervention arm served as an enhancement strategy in case of poor compliance to fatty fish consumption over the year. The primary outcomes were change in body weight, BMI and percentage body fat. Secondary outcomes included change in cardiovascular disease risk factors. Recruitment was by media advertisements and emails sent by the research team throughout Wollongong, a major coastal city $70 \mathrm{~km}$ south of Sydney, Australia. This study was conducted according to Declaration of Helsinki guidelines and procedures were approved by the University of Wollongong Human Research Ethics Committee. Written informed consent was obtained from all participants. This trial is registered at http://www.anzctr. org.au (ID: ACTRN12608000425392).

\section{Randomisation and blinding}

A researcher independent of the subject interface undertook the randomisation of participants into diet groups (stratified by sex and block randomised; nQuery Advisor V 7.0, Statistical solutions, Cork, Ireland) and the code was kept from the researchers collecting dietary data and delivering treatment. Supplements were coded offsite. Different dietitians collected dietary data and provided dietary advice. Those providing advice were necessarily aware of diet category but not of supplement allocation.

\section{Participants}

The study sample comprised middle aged (mean \pm SD age $45 \pm 10$ y) obese adults (mean \pm SD BMI $31.3 \pm$ $3.5 \mathrm{~kg} / \mathrm{m}^{2}$ ). Inclusion criteria included: age between 18 to 60 years, BMI between 25 to $37 \mathrm{~kg} / \mathrm{m}^{2}$, waist circumference $>94 \mathrm{~cm}$ (men) or $>80 \mathrm{~cm}$ (women), otherwise healthy. Individuals with major illnesses, diabetes mellitus, $\mathrm{LDL} \geq 6 \mathrm{mmol} / \mathrm{L}$, food allergies or habits inhibiting compliance, low literacy, inadequate conversational English, and those who are already taking fish oil supplements, unable to undertake study requirements, pregnant/lactating, not weight stable (within $3 \mathrm{~kg}$ ) in the past 6 months or on a weight-loss diet were excluded from participation. Participants were not paid.

\section{Dietary intervention}

The intervention addressed dietary intake at the, food (fish), key nutrient (LCn3PUFA) and whole diet (low calorie) level. The fatty fish target and LCn3PUFA equivalent reference value were based on materials in the Nutrient Reference Values (NRVs) report for Australia and New Zealand [17]. These suggested two servings $(180 \mathrm{~g})$ of fatty fish per week and a dietary intake for LCn3 PUFA based on the $90^{\text {th }}$ percentile of population consumption levels (i.e. $610 \mathrm{mg} /$ day for men and $430 \mathrm{mg} /$ day for women) [17]. All groups were advised on a hypocaloric diet (2 MJ energy below estimated energy requirements estimated by the Mifflin equation [18] with 1.25 physical activity factor), targeting $25 \%$ energy from protein, $45 \%$ energy from carbohydrate and 30\% energy from fat. Diets referred to low fat staple foods (fruit, vegetables, cereals, lean meat, low fat milk and yoghurt) and small amounts of nuts, seeds, spreads and oils. Food groups were congruent with the Australian Guide to Healthy Eating [19], and formed the basis of the standardised procedure for both diet groups and the template of the diets sheets. Participants in the Fish and Fish $+\mathrm{S}$ advice groups were specifically encouraged to consume $180 \mathrm{~g}$ fatty fish per week. Participants in the control group were not given specific advice regarding fish intake, but were instructed to consume prescribed amounts of foods rich in protein, of which fish was an option. Dietary education was supported by print resources outlining methods of cooking the appropriate fish and recipes. The Control and Fish groups were given placebo capsules $(1 \mathrm{~g}$ olive oil per day) and the Fish $+\mathrm{S}$ group the active supplements (420 mg EPA + 210 mg DHA; Blackmore's Promega Heart, Blackmores Australia). Dietary education (1 hour) and follow-up $(30 \mathrm{~min})$ with one of seven experienced dietitians was provided at $0,1,2,3,6,9$, and 12 months 
with written materials and monthly newsletters to support compliance. Accredited Practising Dietitians collected dietary data at 0,3 and 12 months via a validated diet history interview (DH) [20]. Dietary data was analysed using the FoodWorks software system (Version 6, 2009, Xyris Software, Spring Hill, QLD, Australia). Reported food intake data was converted to intakes of energy and macronutrients using the AUSNUT1999 [21] and AusFood2001 databases (revision 11, from FoodWorks 2009 version 6, Xyris Software, Spring Hill, QLD, Australia). Reported LCn3PUFA intakes were assessed separately using the AUSNUT2007 database [22]. The percentage fish in each dish or product was calculated based on a validated approximation of canned fish labels [23] and standardized recipe data. Habitual physical activity at baseline and 12 months was assessed by questionnaire [24]. Advice was given to all groups to walk for 30 minutes three days per week.

\section{Measurement of anthropometric and biochemical variables}

Height was measured using a stadiometer without shoes. Body weight was measured in an upright position in minimal clothing, without shoes using digital scales with a bioelectrical impedance component (Tanita TBF-622; W.W. Wedderburn Pty Ltd, Ingleburn, NSW, Australia) at baseline and every 3 months until 12 months. Percentage body fat was measured using DEXA (Hologic QDR 4500; Hologic Inc. Bedford MA) from most participants at baseline $(n=104), 3$ months $(n=66)$ and 12 months $(n=46)$.

Fasting blood samples taken at 0, 3, 6, 9 and 12 months were sent to a quality assured laboratory (Southern IML Pathology) to measure total cholesterol, HDL, LDL, triglycerides, insulin, and glucose. Leptin was assessed by the same laboratory for samples collected at 0,3 and 12 months. Erythrocyte fatty acid concentrations at 0, 3 and 12 months, a measure of dietary compliance [25], were analysed at Australian Research Laboratories (now Healthscope Pathology), Melbourne, Australia. The omega-3 index was calculated as erythrocyte $[\mathrm{EPA}+\mathrm{DHA}] /[$ total fatty acids] $\times 100 \%$ [26]. Insulin resistance was assessed by HOMA equations [27]. Blood pressure was measured using a medical grade blood pressure monitor (Dinamap XL Vital Signs Monitor). Participants sat for 10 mins then three readings were taken from the same arm, and the mean of the three readings was used as the final reading.

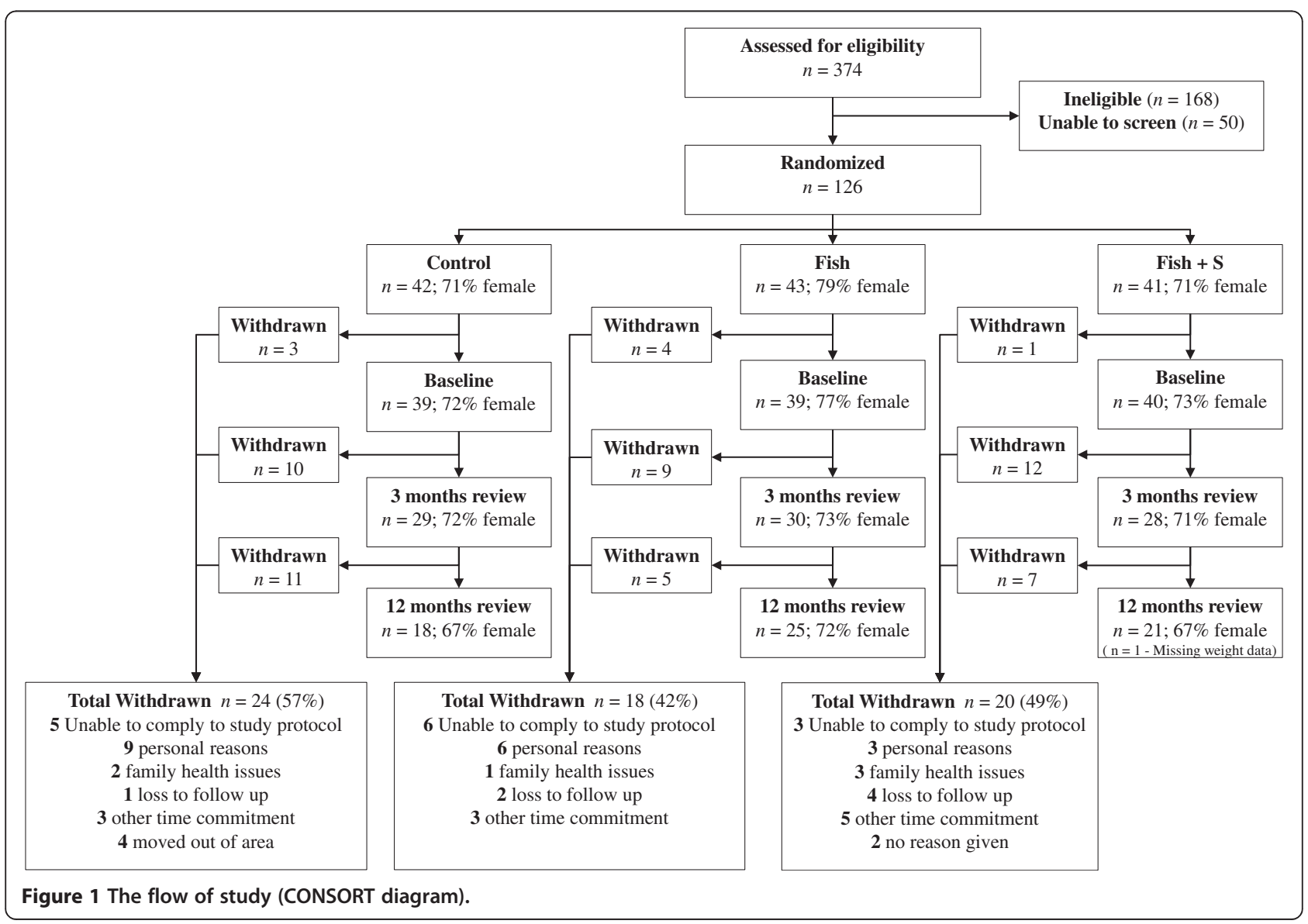




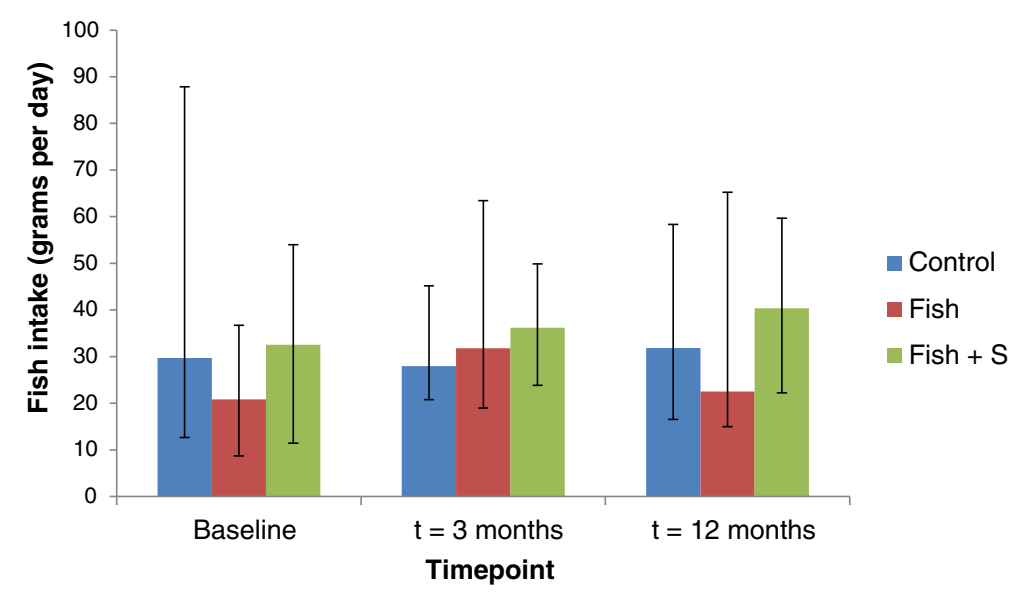

Figure 2 Fish consumption at baseline, 3 months and 12 months.

\section{Compliance to study protocol}

Compliance to fish and supplement recommendations was calculated for all participants who remained in the trial at 12 months. In order to calculate compliance to fish recommendations, an average of each participant's fish intake from all available diet histories was taken, as described by Alhassan et al [28]. Compliers were defined as consuming $<180 \mathrm{~g}$ fish/week for the control group, consuming $\geq 180 \mathrm{~g}$ fish/week for the Fish group, and either consuming $\geq 180 \mathrm{~g}$ fish/week or taking $\geq 90 \%$ of the supplements in the Fish $+\mathrm{S}$ group.

\section{Power calculations}

Using data from a previous study [29] and an expected weight change of $-2.6 \mathrm{~kg}$ in the control and $-4.7 \mathrm{~kg}$ in the intervention groups, we required 27 participants in each group to achieve statistical significance $(\alpha=0.05$, $\beta=0.9$ ). As shown in Figure 1, we enrolled 126 people, from an initial pool of 374 volunteers. Eight participants withdrew from the study before treatment so their data were excluded from all analyses.

\section{Statistical analysis}

All statistical analyses were performed using IBM SPSS (version 17.0 and 19.0, IBM Australia, Lane Cove, NSW, Australia). Analysis of the primary outcome (i.e. weight) was performed on an intention to treat basis with the 118 participants who provided baseline data, using a linear mixed model. Several approaches were taken to investigate the effect of missing data on the primary

Table 1 Subject characteristics at baseline

\begin{tabular}{|c|c|c|c|c|c|c|c|}
\hline Variable & $\begin{array}{c}\text { All subjects who has } \\
\text { baseline data }\end{array}$ & Completers & Dropouts & $p$ value ${ }^{\#}$ & Compliers & Non-compliers & $p$ value ${ }^{*}$ \\
\hline$n$ & 118 & 63 & 55 & - & 36 & 27 & - \\
\hline Age (years) & $45.1 \pm 8.4$ & $45.4 \pm 9.2$ & $44.9 \pm 7.4$ & 0.751 & $47.1 \pm 8.3$ & $43.1 \pm 10.0$ & 0.092 \\
\hline Male (\%) & 26.3 & 31.7 & 20.0 & 0.148 & 30.6 & 33.3 & 0.815 \\
\hline Weight (kg) & $88.6 \pm 12.1$ & $88.5 \pm 12.5$ & $88.7 \pm 11.6$ & 0.921 & $89.5 \pm 12.2$ & $87.1 \pm 13.1$ & 0.444 \\
\hline BMI $\left(\mathrm{kg} / \mathrm{m}^{2}\right)$ & $31.2 \pm 3.5$ & $30.9 \pm 3.6$ & $31.6 \pm 3.4$ & 0.302 & $31.6 \pm 3.5$ & $29.9 \pm 3.5$ & 0.069 \\
\hline Smokers (\%) & 5.9 & 6.3 & 5.5 & 0.837 & 8.3 & 3.7 & 0.456 \\
\hline Education level TAFE or above (\%) & 64.4 & 68.3 & 60.0 & 0.350 & 55.6 & 85.2 & 0.012 \\
\hline Labour intensive job (\%) & 35.0 & 33.3 & 37.0 & 0.713 & 36.1 & 29.6 & 0.359 \\
\hline Taking regular medication (\%) & 26.3 & 20.6 & 32.7 & 0.137 & 22.2 & 18.5 & 0.719 \\
\hline \multicolumn{8}{|l|}{ Country of birth (\%) } \\
\hline Oceania & 83.6 & 87.1 & 79.6 & & 85.7 & 88.9 & \\
\hline Europe & 12.1 & 9.7 & 14.8 & 0.552 & 11.4 & 7.4 & 0.858 \\
\hline Others & 4.3 & 3.2 & 5.6 & & 2.9 & 3.7 & \\
\hline
\end{tabular}

Values are mean \pm SD or percentages. $p$ values obtained using ANOVA for continuous variables and Pearson's Chi's square for categorical variables. ${ }^{\#} p$ value for differences between completers and dropouts.

* $p$ value for differences between compliers and non-compliers.

'Labour intensive jobs included: carer, home duties, retail and trade professionals. 
Table 2 Weight of participants at baseline, 3 months and 12 months

\begin{tabular}{|c|c|c|c|c|c|c|c|c|c|c|c|c|}
\hline & \multicolumn{3}{|c|}{ Control } & \multicolumn{3}{|c|}{ Fish } & \multicolumn{3}{|c|}{ Fish $+S$} & \multicolumn{3}{|c|}{$p$ values } \\
\hline & Baseline & 3 months & 12 months & Baseline & 3 months & 12 months & Baseline & 3 months & 12 months & Time & Group & Interaction \\
\hline \multicolumn{13}{|c|}{ Mixed model with all available data only } \\
\hline$n$ & 39 & 29 & 18 & 39 & 30 & 25 & 40 & 28 & 20 & - & - & - \\
\hline \multirow[t]{2}{*}{ Mean \pm SD } & $88.5 \pm 12.7$ & $84.2 \pm 12.6$ & $81.7 \pm 14.1$ & $90.0 \pm 12.2$ & $84.8 \pm 12.3$ & $80.9 \pm 12.7$ & $88.5 \pm 11.4$ & $82.9 \pm 11.7$ & $84.3 \pm 11.7$ & $<0.001$ & 0.682 & 0.326 \\
\hline & & & & & & & & & & $<0.001^{\ddagger}$ & $0.617^{\ddagger}$ & $0.338^{\ddagger}$ \\
\hline \multicolumn{13}{|c|}{ Mixed model with missing values imputed } \\
\hline$n$ & 39 & 39 & 39 & 39 & 39 & 39 & 40 & 40 & 40 & - & - & - \\
\hline Mean \pm SD & $88.5 \pm 12.7$ & $83.7 \pm 12.0$ & $82.9 \pm 13.0$ & $90.0 \pm 12.2$ & $86.0 \pm 12.3$ & $84.7 \pm 13.2$ & $88.5 \pm 11.4$ & $83.8 \pm 11.3$ & $83.7 \pm 11.3$ & $<0.001$ & 0.767 & 0.803 \\
\hline \multicolumn{13}{|l|}{ LOCF $^{\#}$} \\
\hline$n$ & 39 & 39 & 39 & 39 & 39 & 39 & 40 & 40 & 40 & - & - & - \\
\hline Mean \pm SD & $88.5 \pm 12.7$ & $84.6 \pm 12.1$ & $83.9 \pm 12.7$ & $90.0 \pm 12.2$ & $86.7 \pm 12.8$ & $85.7 \pm 13.6$ & $88.5 \pm 11.4$ & $85.2 \pm 11.5$ & $85.3 \pm 11.7$ & $<0.001$ & 0.805 & 0.457 \\
\hline \multicolumn{13}{|l|}{$B O C F^{\#}$} \\
\hline$n$ & 39 & 39 & 39 & 39 & 39 & 39 & 40 & 40 & 40 & - & - & - \\
\hline Mean \pm SD & $88.5 \pm 12.7$ & $84.6 \pm 12.1$ & $84.8 \pm 13.1$ & $90.0 \pm 12.2$ & $86.7 \pm 12.8$ & $86.0 \pm 14.0$ & $88.5 \pm 11.4$ & $85.2 \pm 11.5$ & $86.0 \pm 11.2$ & $<0.001$ & 0.840 & 0.348 \\
\hline \multicolumn{13}{|c|}{ Completers only ${ }^{\#}$} \\
\hline$n$ & 18 & 18 & 18 & 25 & 25 & 25 & 20 & 20 & 20 & - & - & - \\
\hline Mean \pm SD & $89.5 \pm 13.9$ & $83.2 \pm 13.0$ & $81.7 \pm 14.1$ & $87.1 \pm 11.8$ & $82.5 \pm 11.8$ & $80.9 \pm 12.7$ & $89.4 \pm 12.3$ & $84.2 \pm 11.4$ & $84.3 \pm 11.7$ & $<0.001$ & 0.799 & 0.141 \\
\hline
\end{tabular}

${ }^{\ddagger}$ Adjusted for omega-3 index (red blood cell EPA + DHA).

${ }^{*} p$ value calculated by repeated measures analysis of variance based on data from five time points (0, 3, 6, 9 and 12 months).

LOCF last observation carried forward; BOCF baseline observation carried forward. 
outcome. These included multiple imputation (using PROC MI in SAS V9.2, SAS Inc. Cary, NC), last observation carried forward (LOCF), and baseline observation carried forward (BOCF). These methods are the most commonly used in weight loss studies [30]. Completers only $(n=63)$ analyses were also performed.

Secondary outcomes were analysed using linear mixed model, using data on all participants. Covariates were included in the models where biologically appropriate, as noted in the results section. Intra-class correlations and chi square analyses were used to examine any potential therapist effect, and none was noted. Statistical significance was set at $p<0.05$.

\section{Results}

After the 3 month intensive phase $n=87$ participants remained in the study and at the 12 month follow up data was available for $\mathrm{n}=64$ (weight data missing for $\mathrm{n}=1$ ). Reasons for attrition are shown in Figure 1. Of the 12 mo completers, $57 \%$ were judged to be compliant, $39 \%(\mathrm{n}=7)$ for the control group who reported $<180 \mathrm{~g}$ fish/week, $48 \%(n=12)$ for the Fish group who reported $\geq 180 \mathrm{~g}$ fish/week, and $85 \%(\mathrm{n}=17)$ for the Fish $+\mathrm{S}$ group who reported $\geq 180 \mathrm{~g}$ fish/week or $\geq 90 \%$ supplements. Actual fish consumption was highly variable (Figure 2). There was no difference between groups in dropout rates ( $\log$ 'rank test, $p=0.872$ ), and the characteristics of participants who withdrew were similar to the completers (Table 1). There were no adverse events, and no changes in medications. Prior to randomization, participants reported plausible usual dietary intakes for the study population, including a median intake of $370 \mathrm{mg}$ (men) and $290 \mathrm{mg}$ (women) LCn3PUFA per day, more than half that of the suggested dietary targets $(610 \mathrm{mg} /$ day for men and $430 \mathrm{mg} /$ day for women). Physical activity scores increased over 12 month, with no significant difference between groups (One-way ANOVA, $p=0.673$ ).

\section{Effects on weight loss and body fat}

In the intention to treat analysis (Table 2) based on the linear mixed model, all groups lost weight at 12 months (Control $-4.5 \mathrm{~kg}$ vs. Fish $-4.3 \mathrm{~kg}$ vs. Fish $+\mathrm{S}-3.3 \mathrm{~kg}$; $p<0.001)$ and percentage body fat significantly decreased (Control: $-1.5 \%$ vs. Fish: $-1.4 \%$ vs. Fish + S: $-0.7 \% ; p<0.001$ ). There were no significant differences between groups for these variables and this result remained after adjustment for EPA + DHA status (Figure 3). All other methods of analysis for the primary outcome similarly showed a significant time effect, with no significant group differences, and restricting the analysis to completers only did not significantly change the results. After stratifying the analysis based on compliance, there was no significant weight loss among non-compliers regardless of dietary assignment (time effect $=0.653$; group effect $=0.371$; interaction $=0.972$ ). Significant weight loss was observed among compliers $(87.7 \mathrm{~kg}$ at baseline vs. $79.7 \mathrm{~kg}$ at 12 months; time effect $=0.034)$; but there was no difference between groups (group effect $=0.299$; interaction $=$ 0.996). The mean weight loss at three months was greater in those who completed the 12 months than those who did not $(-5.2$ vs. $-3.2 \mathrm{P}=0.005)$.

\section{Effects on cardiovascular disease risk factors and biomarkers} All groups showed improvements in fasting insulin, HOMA-IR and triglycerides (Table 3). Systolic blood pressure, fasting glucose, total cholesterol and leptin levels decreased for the entire study sample, with no difference between groups. There was a significant time by group interaction for self-reported intake of LCn3PUFA (Table $4, p=0.034$ ), confirmed by a significant group difference in erythrocyte omega-3 index (Table 3, $p=0.009$ ). This effect was primarily due to changes in the Fish $+\mathrm{S}$ group, and post hoc analysis revealed a significant difference between the Fish and Fish $+\mathrm{S}$ groups (Fish: $3.4 \pm 1.0 \%$ vs. Fish + S: $4.4 \pm 1.6 \% ; p=0.007$ ).

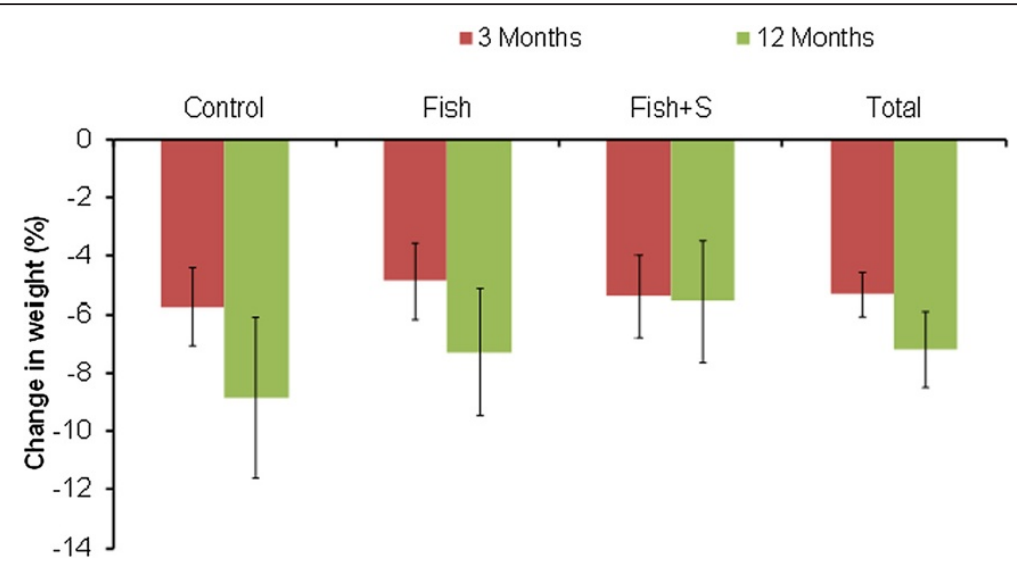

Figure 3 Change in \% body weight by group at 3 and 12 months. 
Table 3 Body mass index, \% body fat and clinical assessments at baseline, 3 months and 12 months

\title{
Variable \\ Body mass index $\left(\mathrm{kg} / \mathrm{m}^{2}\right) \dagger$
}

Control

Baseline $\quad 39$

$30.9 \pm 3.5$

3 months 29

$29.3 \pm 3.4$

12 months

18

$28.0 \pm 3.6$

\section{Body fat (\%)†\#}

$\begin{array}{llll}\text { Baseline } & 34 & 36.7 \pm 7.3 & 36 \\ 3 \text { months } & 21 & 33.4 \pm 7.7 & 25 \\ 12 \text { months } & 14 & 34.4 \pm 7.6 & 16\end{array}$

Fasting glucose level ( $\mathrm{mmol} / \mathrm{L}) \dagger$

$\begin{array}{llll}\text { Baseline } & 37 & 5.0 \pm 0.5 & 39 \\ 3 \text { months } & 27 & 4.9 \pm 0.5 & 30 \\ 12 \text { months } & 17 & 5.1 \pm 0.4 & 24\end{array}$

Fasting insulin level $(\mathrm{mU} / \mathrm{L}) \dagger \neq$

$\begin{array}{llll}\text { Baseline } & 37 & 9.1(7.7-12.9) & 39 \\ 3 \text { months } & 27 & 8.7(7.1-11.5) & 29 \\ 12 \text { months } & 18 & 8.5(6.3-10.5) & 24\end{array}$

$$
\begin{aligned}
& 9.6(7.4-13.8) \\
& 9.1(7.4-12.2) \\
& 8.2(6.2-11.1)
\end{aligned}
$$

$$
\text { Fish }
$$

$38.0 \pm 7.5$
$35.5 \pm 7.6$
$37.4 \pm 8.1$

\begin{tabular}{l}
\hline$n$ \\
40 \\
28 \\
20
\end{tabular}

Fish + S

$5.1 \pm 0.5$

$5.0 \pm 0.6$

$4.9 \pm 0.7$

\begin{abstract}
$5.3 \pm 0.8$
$5.0 \pm 0.8$
\end{abstract}

$5.2 \pm 1.0$

\begin{abstract}
$5.3 \pm 1.2$
$4.8 \pm 0.8$

$4.6 \pm 0.7$
\end{abstract}

\section{Fasting triglycerides ( $\mathrm{mmol} / \mathrm{L}) \dagger \neq$}

Baseline

3 months

$$
37
$$

$1.4(0.9-2.0)$

12 months

$$
1.3(0.9-1.6)
$$

$1.0(0.7-1.5)$

Fasting HDL cholesterol ( $\mathrm{mmol} / \mathrm{L}) \dagger$

Baseline

$$
1.5 \pm 0.4
$$

3 months

$1.5 \pm 0.3$

12 months

$1.4 \pm 0.3$

Fasting LDL cholesterol ( $\mathrm{mmol} / \mathrm{L}) \dagger$

$\begin{array}{ll}\text { Baseline } & 37 \\ 3 \text { months } & 27 \\ 12 \text { months } & 18\end{array}$

$$
\begin{aligned}
& 3.1 \pm 1.1 \\
& 2.7 \pm 0.8
\end{aligned}
$$$$
2.7 \pm 0.8
$$

Fasting leptin $(\mathrm{mg} / \mathrm{mL}) 9 \neq$

$\begin{array}{llll}\text { Baseline } & 37 & 21.5(11.7-31.3) & 38 \\ 3 \text { months } & 27 & 11.8(7.2-20.5) & 30 \\ 12 \text { months } & 18 & 10.7(5.6-16.3) & 24\end{array}$

Systolic blood pressure $(\mathrm{mmHg})$

$\begin{array}{lll}\text { Baseline } & 37 & 126 \pm 16 \\ 3 \text { months } & 27 & 125 \pm 12 \\ 12 \text { months } & 16 & 120 \pm 11\end{array}$

Diastolic blood pressure $(\mathrm{mmHg})$

$\begin{array}{lll}\text { Baseline } & 37 & 74 \pm 10 \\ 3 \text { months } & 27 & 74 \pm 9\end{array}$

$1.3(1.0-1.8)$
$1.3(1.0-1.5)$
$1.1(0.9-1.4)$

$1.5 \pm 0.4$
$1.4 \pm 0.3$
$1.4 \pm 0.4$

$1.4 \pm 0.4$

$$
\begin{aligned}
& 3.1 \pm 0.8 \\
& 3.0 \pm 0.8
\end{aligned}
$$$$
3.2 \pm 0.9
$$

$$
\begin{gathered}
19.9(12.3-29.6) \\
14.7(7.2-20.8)
\end{gathered}
$$$$
14.1(7.2-23.3)
$$

Value

Effect

$31.6 \pm 3.4$
$29.6 \pm 3.1$
$29.8 \pm 3.5$

$36.0 \pm 8.7$
$33.0 \pm 10.3$
$34.0 \pm 10.2$

$34.0 \pm 10.2$

$5.0 \pm 0.6$

$4.7 \pm 0.6$

$4.8 \pm 0.4$

$12.0(8.5-17.0)$

$10.4(7.2-13.0)$

$9.2(6.5-13.1)$

$$
\begin{aligned}
& 5.2 \pm 0.9 \\
& 5.1 \pm 0.9
\end{aligned}
$$$$
5.4 \pm 0.9
$$

$$
\begin{aligned}
& 1.3(1.0-2.1) \\
& 1.1(0.7-1.7)
\end{aligned}
$$$$
1.0(0.6-1.5)
$$

Time

Group

Interaction

$$
\begin{aligned}
& \text { Time } \\
& \text { Group }
\end{aligned}
$$

Interaction

$$
\begin{aligned}
& \text { Time } \\
& \text { Group }
\end{aligned}
$$$$
\text { Interaction }
$$$$
\text { Time }
$$$$
\text { Group }
$$$$
\text { Interaction }
$$
$p$ value*

0.001

0.376

0.370

0.001

595

0.369

0.009

0.585

0.350

0.001

0.360

0.086

$\begin{array}{cc}\text { Time } & <0.001 \\ \text { Group } & 0.309 \\ \text { Interaction } & 0.098\end{array}$

$\begin{array}{cc}\text { Time } & <0.001 \\ \text { Group } & 0.661 \\ \text { Interaction } & 0.122\end{array}$

Interaction

0.122

$1.4 \pm 0.4$

Time

$<0.001$

Group

0.566

$1.5 \pm 0.4$

Interaction

0.739

$$
\begin{aligned}
& 3.1 \pm 0.8 \\
& 3.1 \pm 0.7
\end{aligned}
$$

Time

0.001

$3.4 \pm 0.9$

Group

0.242

0.091

Interaction

$<0.001$

0.682

$14.1(7.0-22.6)$

Time

0.083

Interaction

0.002

0.673

$116 \pm 12$

Time

0.118

Interaction

0.079

$72 \pm 9$

Time

0.990 
Table 3 Body mass index, \% body fat and clinical assessments at baseline, 3 months and 12 months (Continued)

\begin{tabular}{lcccccccc}
\hline $\begin{array}{l}\text { 12 months } \\
\text { HOMA-IR }\end{array}$ & 16 & $72 \pm 7$ & 23 & $77 \pm 10$ & 20 & $74 \pm 9$ & Interaction & 0.112 \\
Baseline & 37 & $1.6 \pm 1.1$ & 39 & $1.5 \pm 0.7$ & 39 & $1.7 \pm 0.7$ & Time & Group \\
3 months & 27 & $1.3 \pm 0.7$ & 29 & $1.5 \pm 0.9$ & 28 & $1.4 \pm 0.5$ & 0.001 \\
12 months & 17 & $1.2 \pm 0.5$ & 24 & $1.2 \pm 0.5$ & 21 & $1.3 \pm 0.5$ & Interaction \\
Omega-3 index (\%) & & & & & 3.326 & Time \\
Baseline & 36 & $4.0 \pm 1.2$ & 38 & $3.5 \pm 1.1$ & 39 & $3.6 \pm 1.1$ & 0.240 \\
3 months & 26 & $3.6 \pm 2.0$ & 30 & $3.6 \pm 1.2$ & 28 & $4.5 \pm 1.7$ & Group & 0.009 \\
12 months & 15 & $3.7 \pm 0.9$ & 23 & $3.4 \pm 1.0$ & 21 & $4.4 \pm 1.6$ & Interaction & 0.116 \\
\hline
\end{tabular}

Values are expressed as mean $\pm \mathrm{SD}$ or median (interquartile range)

HOMA-IR, homeostasis model assessment of insulin resistance.

*Linear mixed model, significance at $p=0.05$.

ILeptin adjusted for body fat.

$t p$ value based on five time points $(0,3,6,9$ and 12 months).

\#Body fat assessed by DEXA.

$\neq$ Ln transformed.

${ }^{* *}$ Erythrocyte $[\mathrm{EPA}+\mathrm{DHA}] /[$ total fatty acids] $\times 100 \%$.

\section{Discussion}

Under free living conditions, advice emphasising 2 fatty fish meals a week did not enhance weight loss achieved through low calorie dietary advice alone. The addition of equivalent amounts of LCn3PUFA supplements slightly increased LCn3PUFA status but did not influence weight loss. The required energy deficit appeared met by the total diet in all treatment groups, making it difficult to attribute effects to advice on fish consumption, even if supplemented with their key nutrients (LCn3PUFA).

From a nutrient perspective, our results are consistent with other shorter term trials $[11,12]$, but possibly for different reasons. The target LCn3PUFA intake was the Nutrient Reference Value for Australia and New Zealand of about $600 \mathrm{mg}$ [31]. The higher biomarker status in the supplemented group suggested that supplements may assure better LCn3PUFA intakes than advice to consume fish, but this did not enhance weight loss. It may be that higher doses are required, although weight loss still was still achieved regardless of supplementation.

Factors that may have affected results, such as accounting for the n-6:n-3 ratio [32] did not change the outcomes. We used a similar approach to supplementation as other studies testing effects of dietary LCn3PUFA in ranges consumed in most populations $(<2 \mathrm{~g} /$ day $)$ and using an olive oil placebo [33]. Our results were consistent with one of our previous trials [29], and while a similar study showed greater improvements in disease risk factors than ours [15], our study was longer (12 months vs. 24 weeks) and our sample was not as overweight, appeared to have lower levels of risk, and our target intake of LCn3PUFA was lower (0.42 g EPA + 0.21 g DHA vs. 1.3 g EPA +2.9 g DHA). We acknowledge that low concentrations of erythrocyte EPA and DHA have been linked with a number of negative health effects [34] but this is a separate issue to weight loss in a low calorie dietary content.

The dietary advice was based on nutrient-rich core foods: vegetables, wholegrain cereals, fruits, lean meats and low fat dairy foods, and we controlled for advice on the total diet. Nevertheless, our results remained congruent with a similar study applying a more liberal ad libitum dietary advice strategy [12]. The considerable variation in fish intakes, demonstrated the difficulty in sustaining levels of fish consumption. The magnitude of effect of the intervention was good, similar to that of a 12 months multicentre trial comparing different dietary advice strategies [4]. Both studies showed no difference in weight loss between diet advice groups with a lack of compliance to actual dietary prescriptions. These studies confirm that dietary energy intake is the main factor in weight loss, but at the same time, the intention to treat analysis provides evidence for the effects of the dietary advice strategy.

As demonstrated in previous research [4], weight loss in our study was associated with significant improvements in a wide range of cardiovascular disease risk factors. In the sample as a whole, we observed significant reductions in systolic blood pressure, glucose, insulin, and insulin resistance. Triglycerides were not significantly reduced, but this was consistent with other findings [15]. The drop in leptin levels across the sample was congruent with reduced energy intakes, as would be expected [35] and did not differ by treatment.

There were limitations to the study. As a feature of long term 'free living' weight loss trials [15], the attrition rate is disappointing, although the level was within the 
Table 4 Reported daily energy, macronutrient and fibre intakes at baseline, 3 months and 12 months

\begin{tabular}{|c|c|c|c|c|c|c|c|c|}
\hline \multirow[t]{2}{*}{ Variable } & \multicolumn{2}{|c|}{ Control } & \multicolumn{2}{|r|}{ Fish } & \multicolumn{2}{|r|}{ Fish + S } & \multicolumn{2}{|c|}{ Difference between groups } \\
\hline & $n$ & Value & $n$ & Value & $n$ & Value & Effect & $p$ value ${ }^{*}$ \\
\hline \multicolumn{9}{|l|}{ Energy $(k J)$} \\
\hline Baseline & 39 & $9230 \pm 2930$ & 39 & $10190 \pm 3970$ & 40 & $10480 \pm 3320$ & Time & $<0.001$ \\
\hline 3 months & 29 & $6600 \pm 1510$ & 29 & $6640 \pm 1550$ & 28 & $6350 \pm 1240$ & Group & 0.581 \\
\hline 12 months & 18 & $7330 \pm 1750$ & 25 & $6760 \pm 1750$ & 21 & $6700 \pm 1490$ & Interaction & 0.185 \\
\hline \multicolumn{9}{|c|}{$\%$ from protein } \\
\hline Baseline & 39 & $19.5 \pm 3.5$ & 39 & $17.8 \pm 3.2$ & 40 & $18.1 \pm 3.1$ & Time & $<0.001$ \\
\hline 3 months & 29 & $23.1 \pm 4.1$ & 29 & $22.4 \pm 3.2$ & 28 & $21.9 \pm 2.7$ & Group & 0.075 \\
\hline 12 months & 18 & $22.5 \pm 3.9$ & 25 & $21.2 \pm 3.8$ & 21 & $21.6 \pm 3.2$ & Interaction & 0.833 \\
\hline \multicolumn{9}{|c|}{$\%$ from fat } \\
\hline Baseline & 39 & $32.4 \pm 5.3$ & 39 & $35.5 \pm 5.9$ & 40 & $34.9 \pm 6.5$ & Time & $<0.001$ \\
\hline 3 months & 29 & $25.0 \pm 6.2$ & 29 & $27.0 \pm 6.3$ & 28 & $24.9 \pm 4.3$ & Group & 0.015 \\
\hline 12 months & 18 & $24.4 \pm 5.6$ & 25 & $29.1 \pm 7.1$ & 21 & $26.9 \pm 5.8$ & Interaction & 0.366 \\
\hline \multicolumn{9}{|c|}{$\% E$ from saturated fat } \\
\hline Baseline & 39 & $12.2 \pm 3.0$ & 39 & $12.7 \pm 3.0$ & 40 & $13.0 \pm 4.0$ & Time & $<0.001$ \\
\hline 3 months & 29 & $8.1 \pm 2.2$ & 29 & $8.0 \pm 2.2$ & 28 & $7.6 \pm 1.6$ & Group & 0.800 \\
\hline 12 months & 18 & $8.5 \pm 2.9$ & 25 & $8.7 \pm 2.7$ & 21 & $8.6 \pm 2.7$ & Interaction & 0.727 \\
\hline \multicolumn{9}{|c|}{$\%$ from polyunsaturated fats } \\
\hline Baseline & 39 & $5.2 \pm 1.9$ & 39 & $13.9 \pm 3.1$ & 40 & $13.6 \pm 3.5$ & Time & 0.570 \\
\hline 3 months & 29 & $4.4 \pm 2.1$ & 29 & $9.6 \pm 2.5$ & 28 & $9.3 \pm 2.2$ & Group & $<0.001$ \\
\hline 12 months & 18 & $3.9 \pm 1.1$ & 25 & $11.3 \pm 3.8$ & 21 & $9.9 \pm 3.1$ & Interaction & 0.153 \\
\hline \multicolumn{9}{|c|}{$\% E$ from monounsaturated fats } \\
\hline Baseline & 39 & $12.0 \pm 2.5$ & 39 & $13.9 \pm 3.1$ & 40 & $13.6 \pm 3.5$ & Time & $<0.001$ \\
\hline 3 months & 29 & $9.8 \pm 3.3$ & 29 & $9.6 \pm 2.5$ & 28 & $9.3 \pm 2.2$ & Group & 0.075 \\
\hline 12 months & 18 & $9.3 \pm 2.5$ & 25 & $11.3 \pm 3.8$ & 21 & $9.9 \pm 3.0$ & Interaction & 0.039 \\
\hline \multicolumn{9}{|l|}{$P: S$ ratio } \\
\hline Baseline & 39 & $0.47 \pm 0.24$ & 39 & $0.50 \pm 0.22$ & 40 & $0.45 \pm 0.19$ & Time & $<0.001$ \\
\hline 3 months & 29 & $0.58 \pm 0.31$ & 29 & $0.88 \pm 0.45$ & 28 & $0.72 \pm 0.29$ & Group & 0.007 \\
\hline 12 months & 18 & $0.50 \pm 0.21$ & 25 & $0.78 \pm 0.59$ & 21 & $0.73 \pm 0.42$ & Interaction & 0.061 \\
\hline \multicolumn{9}{|c|}{ Long chain $n-3$ polyunsaturated fatty acids (mg)†キ } \\
\hline Baseline & 39 & $292(195-760)$ & 39 & $310(198-446)$ & 40 & $310(167-474)$ & Time & 0.085 \\
\hline 3 months & 29 & $314(178-456)$ & 29 & $430(219-917)$ & 28 & $512(272-706)$ & Group & 0.595 \\
\hline 12 months & 18 & $393(195-521)$ & 25 & $421(129-675)$ & 21 & $355(178-815)$ & Interaction & 0.034 \\
\hline \multicolumn{9}{|c|}{$\% E$ from carbohydrates } \\
\hline Baseline & 39 & $41.5 \pm 6.0$ & 39 & $40.8 \pm 6.1$ & 40 & $43.4 \pm 6.8$ & Time & $<0.001$ \\
\hline 3 months & 29 & $43.2 \pm 10.9$ & 29 & $44.7 \pm 7.3$ & 28 & $47.8 \pm 5.5$ & Group & 0.026 \\
\hline 12 months & 18 & $45.6 \pm 6.0$ & 25 & $43.4 \pm 6.6$ & 21 & $46.1 \pm 4.9$ & Interaction & 0.457 \\
\hline \multicolumn{9}{|c|}{$\%$ from alcohol } \\
\hline Baseline & 39 & $4.9 \pm 5.2$ & 39 & $4.3 \pm 4.3$ & 40 & $2.3 \pm 3.4$ & Time & 0.611 \\
\hline 3 months & 29 & $4.8 \pm 4.8$ & 29 & $3.5 \pm 3.8$ & 28 & $2.9 \pm 4.3$ & Group & 0.159 \\
\hline 12 months & 18 & $5.4 \pm 6.0$ & 25 & $4.0 \pm 5.0$ & 21 & $3.0 \pm 3.9$ & Interaction & 0.218 \\
\hline \multicolumn{9}{|c|}{ Dietary cholesterol (mg) } \\
\hline Baseline & 39 & $308 \pm 135$ & 39 & $322 \pm 222$ & 40 & $312 \pm 113$ & Time & $<0.001$ \\
\hline 3 months & 29 & $213 \pm 68$ & 29 & $211 \pm 64$ & 28 & $191 \pm 64$ & Group & 0.827 \\
\hline
\end{tabular}


Table 4 Reported daily energy, macronutrient and fibre intakes at baseline, 3 months and 12 months (Continued)

\begin{tabular}{|c|c|c|c|c|c|c|c|c|}
\hline 12 months & 18 & $242 \pm 89$ & 25 & $191 \pm 63$ & 21 & $209 \pm 73$ & Interaction & 0.885 \\
\hline \multicolumn{9}{|c|}{ Dietary fibre $(\mathrm{g})$} \\
\hline Baseline & 39 & $25.7 \pm 8.4$ & 39 & $28.5 \pm 9.4$ & 40 & $28.6 \pm 12.4$ & Time & 0.008 \\
\hline 3 months & 29 & $23.9 \pm 6.1$ & 29 & $25.6 \pm 5.9$ & 28 & $26.1 \pm 4.9$ & Group & 0.535 \\
\hline 12 months & 18 & $25.2 \pm 5.8$ & 25 & $25.1 \pm 6.5$ & 21 & $25.3 \pm 5.7$ & Interaction & 0.855 \\
\hline
\end{tabular}

Values are expressed as mean \pm SD or median (interquartile range).

$\mathrm{P}: \mathrm{S}$ ratio, polyunsaturated fatty acid to saturated fatty acid ratio.

*Linear mixed model, significance at $p=0.05$.

tLn transformed.

fLC n-3 includes: 20:3n3 (eicosatrienoic acid), 20:5n3 (eicosapentaenoic acid), 22:5n3 (docosapentaenoic acid) and 22:6n3 (docosahexaenoic acid). Dietary data did not include supplementation.

range of reporting [16]. We applied state of the art statistical analyses and while we acknowledge some limitations [36] to the BOCF and LOCF methods, these are the most commonly used in the weight loss RCT literature [15]. The assumption that those who lost more weight are more likely to complete is also considered in the analysis. We saw little influence of attrition on results, drawing conclusions from the intention to treat analysis vs. completers only analysis, and between the characteristics of completers vs. dropouts.

The hypothesised effect was a difference in favour of the treatment group (fish emphasis) of a weight loss of $2.1 \mathrm{~kg}$ greater than the control (no fish emphasis). The results show that the confidence intervals for the between group differences in the completers do not include this value. In addition, the difference between the Control and Fish arm $(-1.6 \mathrm{~kg}, 95 \% \mathrm{CI}-5.1,1.8$ in favour of control) in the completers did not support the alternate hypothesis that emphasising fish in the dietary advice has a greater weight loss effect. This was still the case with the Control and Fish + Supps (-2.7 kg 95\% CI-6.4,0.9 kg) where we had enhanced the advice with fish oil supplements. The upper CI of both intervention arms shows a value that is not statistically significant. (Additional file 1: supplementary Tables S1 and S2 show similar lack of differences between completers for change in dietary intake and other outcomes at 12 months). A greater weight loss of 0.9 or $1.8 \mathrm{~kg}$ in the treatment groups compared with the control may be too small to be considered clinically relevant after $12 \mathrm{mo}$. Future studies could use our results to estimate sample sizes for equivalence or use the variance estimates to determine difference needed for effect.

A major strength of our study was that the trial extended to 12 months follow up [37], with regular monitoring and continual engagement with the participants to motivate sustained dietary change. Compliance with the supplement regimen was confirmed with erythrocyte fatty acid concentrations. By basing dietary advice in all groups on core foods, we addressed the lack of dietary controls and variation in food sources which often hampers studies of dietary fat [38].

\section{Conclusions}

Advice to consume 2 fish meals per week did not appear to enhance the effects on weight loss of a healthy low calorie diet, however further studies with greater power may be required to make this conclusion. In considering the relative roles of nutrients, food and whole diets [3], we conclude that the whole diet may the most tangible nutritional parameter in deriving evidence for food effects in weight loss studies.

\section{Additional file}

Additional file 1: Table S1. 12-month change from baseline (95\% Confidence Intervals) in dietary variables by group, amongst completers only. Table S2. 12-month change from baseline (95\% Confidence Intervals) in outcome variables by group amongst completers only.

\section{Competing interests}

The authors declare they have no competing interests.

\section{Authors' contributions}

LT - designed the research, wrote the paper and had primary responsibility for the final manuscript. MB - contributed to study design, performed the randomisation process and undertook statistical analysis. KC - contributed to study design and contributed to manuscript. YP - provided essential materials for the construction of databases, contributed to manuscript and conducted research at the clinical interface. EN - provided essential materials for the construction of databases, contributed to manuscript and conducted research at the clinical interface. $\mathrm{JO}$ - conducted the research at the clinical interface, contributed to manuscript and provided key summaries and preparation of data. RT - conducted research at the clinical interface, contributed to manuscript and assisted in the preparation of data and submission of the final document. QS - Conducted research at the clinical interface. $J L$ - contributed to final manuscript and undertook statistical analysis. All authors read and approved the final manuscript.

\section{Acknowledgements}

The research was undertaken in facilities of the School of Health Sciences, University of Wollongong. Acknowledgements go to Dr Sheila West for review comments on earlier versions and to staff and students of the School of Health Sciences for technical and other support provided in the conduct of the study.

This work was funded by the Australian National Health and Medical Research Council (project grant number 514631). Omega-3 PUFA supplement and placebo capsules were provided without cost by Blackmores Australia.

Received: 3 July 2013 Accepted: 12 December 2013 Published: 26 December 2013 
References

1. National Health and Medical Research Council: Australian dietary guidelines. Canberra: National Health and Medical Research Council; 2013.

2. U.S. Department of Agriculture and U.S. Department of Health and Human Services: Dietary Guidelines for Americans. 7th edition. Washington D.C: US Government Printing Office; 2010. December 2010.

3. Mozaffarian D, Ludwig D: Dietary guidelines in the 21st century - a time for food. J Am Med Assoc 2010, 304(6):681.

4. Sacks FM, Bray GA, Carey VJ, Smith SR, Ryan DH, Anton SD, McManus K, Champagne CM, Bishop LM, Laranjo N, et al: Comparison of weight-loss diets with different compositions of fat, protein, and carbohydrates. N Engl J Med 2009, 360(9):859-873.

5. National Health and Medical Research Council: A review of the evidence to address targeted questions to inform the revision of the Australian Dietary Guidelines - Evidence Statements. Canberra: Commonwealth of Australia; 2011

6. Micallef M, Munro I, Phang M, Garg M: Plasma n-3 polyunsaturated fatty acids are negatively associated with obesity. Br J Nutr 2009 102:1370-1374.

7. Garaulet M, Perez-Llamas F, Perez-Ayala M, Martinez P, de Medina FS, Tebar FJ, Zamora S: Site-specific differences in the fatty acid composition of abdominal adipose tissue in an obese population from a Mediterranean area: relation with dietary fatty acids, plasma lipid profile, serum insulin and central obesity. Am J Clin Nutr 2001, 74(5):585-591.

8. Kabir M, Skurnik G, Naour N, Pechtner V, Meugnier E, Rome S, QuingardBoulane A, Vidal H, Slama G, Clement K, et al: Treatment for 2 mo with n-3 polyunsaturated fatty acids reduces adiposity and some atherogenic factors but does not improve insulin sensitivity in women with type 2 diabetes: a randomized controlled study. Am J Clin Nutr 2007, 86:1670-1679.

9. Couet C, Delarue J, Ritz P, Antoine J, Lamisse F: Effect of dietary fish oil on body fat mass and basal fat oxidation in healthy adults. Int J Obes 1997, 21:637-643.

10. Kunesova M, Braunerova R, Hlavaty P, Tvrzicka E, Stankova B, Skrrha J, Hilgertova J, Hill M, Kopecky J, Wagenknecht M, et al: The influence of n-3 polyunsaturated fatty acids and very low calorie diet during a short-term weight reducing regimen on weight loss and serum fatty acid composition in severely obese women. Physiol Res 2006, 55:63-72.

11. de Fina L, Marcoux L, Devers S, Cleaver J, Willis B: Effects of omega-3 supplementation in combination with diet and exercise on weight loss and body composition. Am J Clin Nutr 2011, 93:455-462.

12. Kratz M, Callahan $H$, Yang $P$, Matthys $C$, Weigle D: Dietary $n-3$ polyunsaturated fatty acids and energy balance in overweight or moderately obese men and women: a randomized controlled trial. Nutr Metab 2009, 6:24.

13. Thorsdottir I, Tomasson H, Gunnarsdottir I, Gisladottir E, Kiely M, Parra M, Bandarra N, Schaafsma G, Martinez J: Randomized trial of weight-loss-diets for young adults varying in fish and fish oil content. Int J Obes 2007 31:1560-1566.

14. Mann Jl, Morenga LT: Diet and diabetes revisited, yet again. Am J Clin Nutr 2013, 97(3):453-454

15. Jebb SA, Ahern AL, Olson AD, Aston LM, Holzapfel C, Stoll J, Amann-Gassner $U$, Simpson AE, Fuller NR, Pearson S, et al: Primary care referral to a commercial provider for weight loss treatment versus standard care: a randomised controlled trial. Lancet 2011, 378(9801):1485-1495.

16. Allison PD: Missing Data. Thousand Oaks, CA: Sage University Papers Series; 2001

17. National Health and Medical Research Council: Nutrient reference values for Australia and New Zealand including recommended dietary intakes. Canberra: NHMRC; 2006

18. Mifflin M, St Jeor S, Hill L, Scott B, Daugherty SA, Koh Y: A new predictive equation for testing energy expenditure in healthy individuals. Am J Clin Nutr 1990, 51:241-247.

19. Department of Health and Ageing: Australian guide to healthy eating. Canberra: Commonwealth of Australia; 1998.

20. Martin GS, Tapsell LC, Batterham M,J, Russell KG: Relative validity of a diet history interview in an intervention trial manipulating dietary fat in the management of type 2 diabetes mellitus. Prev Med 2003, 36:420-428.

21. Food Standards Australia New Zealand: AUSNUT - Australian Food and Nutrient Database 1999. Canberra: Food Standards Australia New Zealand; 1999.
22. Food Standards Australia New Zealand: AUSNUT 2007 - Australian Food Supplement and Nutrient Database for Estimation of Population Nutrient Intakes. Canberra: Food Standards Australia New Zealand; 2008.

23. Neale E, Probst Y, Batterham M, Tapsell L: Development and Validation of an Australian Database for estimating the Seafood Content of Canned Products. Food and Nutrition Sciences 2011, 2(7):759-763.

24. Baecke J, Burema J, Frijters J: A short questionnaire for the measurement of habitual physical activity in epidemiological studies. Am J Clin Nutr 1982, 36:936-942

25. Patel P, Sharp S, Jansen E, Luben R, Khaw K, Wareham N, NG F: Fatty acids measured in plasma and erythrocyte-membrane phospholipids and derived by food-frequency questionnaire and the risk of new-onset type 2 diabetes: a pilot study in the European Prospective Investigation into Cancer and Nutrition (EPIC)-Norfolk cohort. Am J Clin Nutr 2010, 92:1214-1222.

26. Harris WS: The omega-3 index as a risk factor for coronary heart disease. Am J Clin Nutr 2008, 87(6):1997S-2002S.

27. Levy J, Matthews D, Hermans M: Correct Homeostasis Model Assessment (HOMA) evaluation uses the computer program. Diabetes Care 1998, 21:2191-2192

28. Alhassan S, Kim S, Bersamin A, King A, Gardner C: Dietary adherence and weight loss success among overweight women: results from the A to $Z$ weight loss study. Int J Obes 2008, 32:985-991.

29. Tapsell L, Batterham M, Huang XF, Tan SY, Teuss G, Charlton K, O' Shea J, Warensjö E: Short term effects of energy restriction and dietary fat sub-type on weight loss and disease risk factors. Nutr Metab Cardiovasc Dis 2010, 20(5):317-325.

30. Elobeid MA, Padilla MA, McVie T, Thomas O, Brock DW, Musser B, Lu K Coffey CS, Desmond RA, St-Onge M-P, et al: Missing Data in Randomized Clinical Trials for Weight Loss: Scope of the Problem, State of the Field, and Performance of Statistical Methods. PLOS One 2009, 4(8):e6624.

31. National Health and Medical Research Council: Reference values for Australia and New Zealand, including recommended dietary intakes. Canberra: NHMRC; 2006.

32. Aihaud F, Guesnet $P$, Cunnane $C$ : An emerging risk factor for obesity: does disequilibrium of polyunsaturated fatty acid metabolism contribute to excessive adipose tissue development? Br J Nutr 2008, 100:461-470.

33. Sanders TA, Hall WL, Maniou Z, Lewis F, Seed PT, Chowienczyk PJ: Effect of low doses of long-chain $n-3$ PUFAs on endothelial function and arterial stiffness: a randomized controlled trial. Am J Clin Nutr 2011, 94(4):973-980.

34. Harris WS, Klurfeld DM: Twentieth-century trends in essential fatty acid intakes and the predicted omega- 3 index: evidence versus estimates. Am J Clin Nutr 2011, 93(5):907-908.

35. Chan J, Mantzoros C: Role of leptin in energy deprivation states:normal human physiology and clinical implications for hypothalamic amenorrhoea and anorexia nervosa. Lancet 2005, 366:74-85.

36. Carpenter JR, Kenward MG: Missing data in randomised controlled trials - a practical guide. Birmingham: National Institute for Health Research, Publication RM03/JH17/MK; 2008.

37. Ludwig DS, Ebbeling CB: Weight-loss maintenance - mind over matter? N Eng J Med 2010, 363:2159-2161.

38. Melanson E, Astrup A, Donahoo W: The relationship between dietary fat and fatty acid intake and body weight, diabetes, and the metabolic syndrome. Ann Nutr Metab 2009, 55:229-243.

doi:10.1186/1471-2458-13-1231

Cite this article as: Tapsell et al:: Foods, nutrients or whole diets: effects of targeting fish and LCn3PUFA consumption in a $12 \mathrm{mo}$ weight loss trial. BMC Public Health 2013 13:1231. 